\title{
Percutaneous Endoscopic Gastrostomy as a Treatment for Chronic Gastric Volvulus
}

We report here the case of a 61-year-old man with a history of chronic bronchitis and diabetes. The patient had received a Björktype mitral prosthetic valve, and was on anticoagulant treatment for chronic atrial fibrillation. He came to the hospital four times in two months, suffering from gastric volvulus (Figure 1).

A surgical approach was rejected, as the patient had several highrisk factors. At his fourth hospital admission, it was decided to carry out a percutaneous endoscopic gastrostomy (PEG) in order to fix the stomach in the correct anatomical position. Twenty-four hours after the placement of the gastrostomy catheter, the patient was put on an oral diet, and he was discharged after 72 hours. After one month, the gastrostomy was removed, and the stomach was checked endoscopically to make sure that it was in a normal anatomical position. The patient continued to be asymptomatic during the subsequent follow-up. A gastrointestinal series carried out six months later showed correct positioning of the stomach (Figure 2). After a 30-month follow-up period, the patient has not experienced any further episodes of volvulus.

PEG was described by Gauderer et al. in 1980 as an alternative to traditional surgical methods for creating gastrostomies for enteral feeding (1-3). Its use in the treatment of chronic idiopathic gastric volvulus was described by Eckhauser and Ferron, who in 1985 published a case in which correction had been achieved by means of a double percutaneous endoscopic gastrostomy. The first catheter was placed on the anterior wall of the antrum, and the second catheter in the gastric body (4). In the case reported here, only a single gastrostomy catheter on the anterior wall of the gastric body proximal to the great curvature was required to

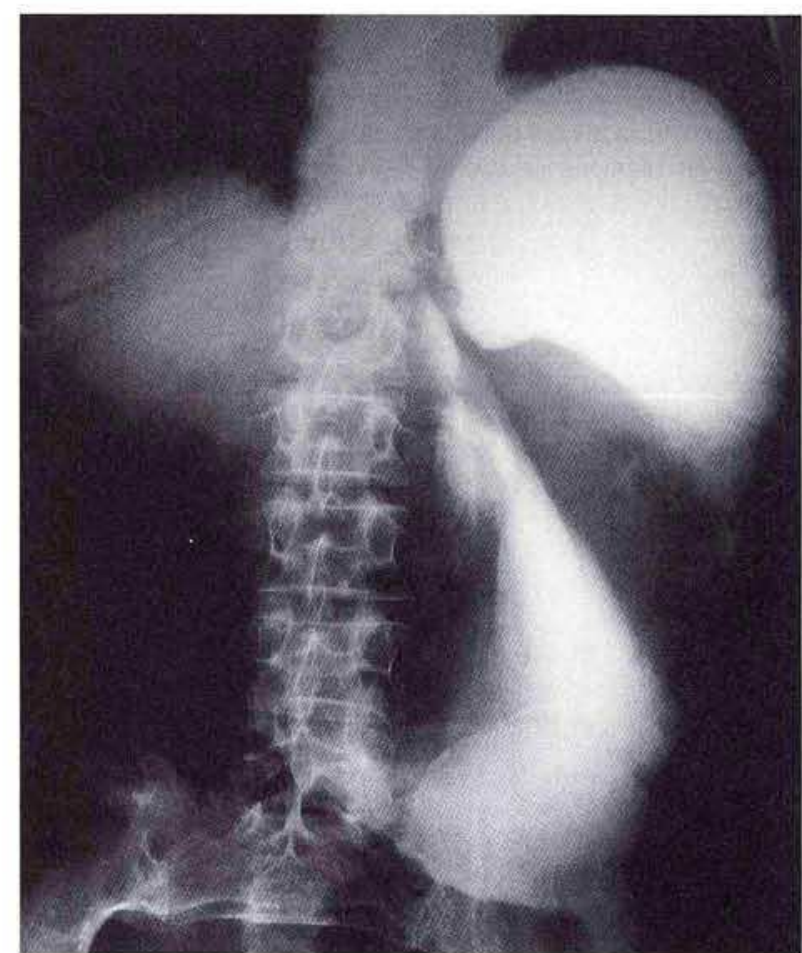

Figure 1: Stomach torsioned "volvulated" on its horizontal axis with no passage of contrast to the duodenum. 


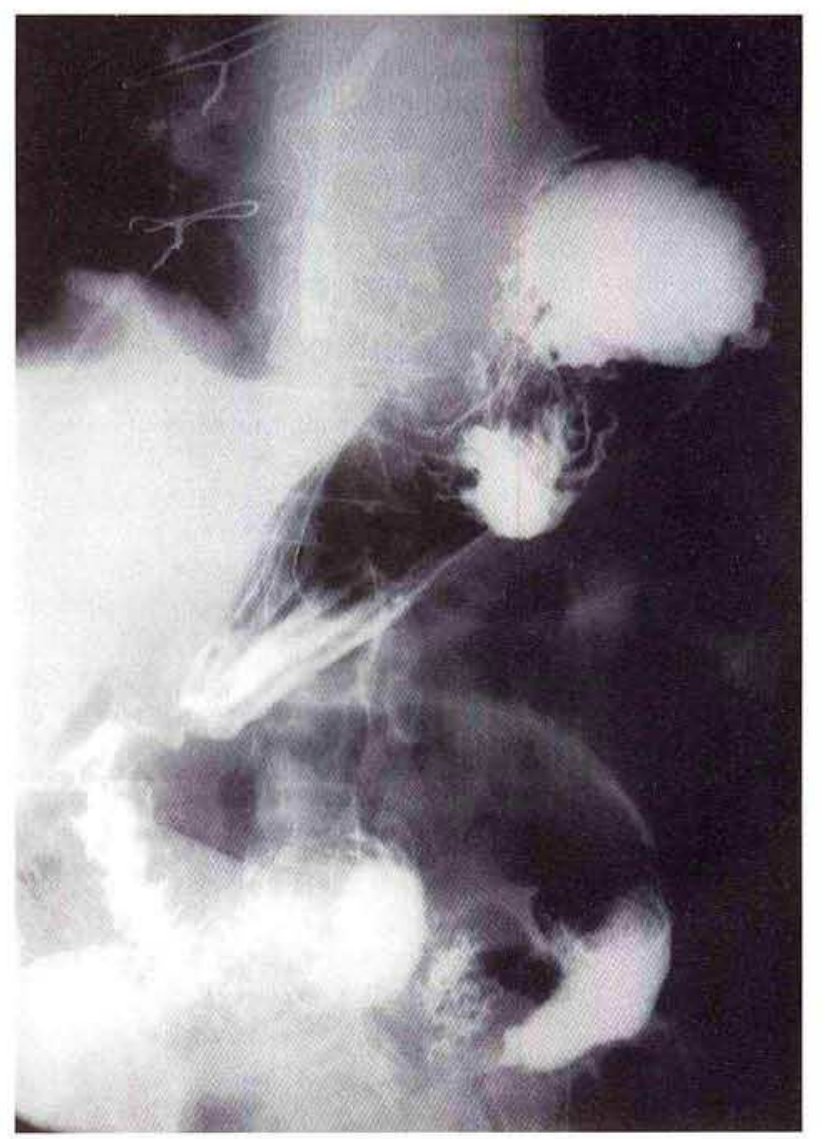

Figure 2: Stomach in a normal position at 6 months after PEG.

correct the condition. The gastrostomy fixes or seals the anterior side of the stomach to the posterior side of the abdominal wall, allowing adhesions to build up between the two surfaces that provide an engaging or sealing mechanism when the catheter is removed.
We believe that in the hands of experienced physicians, PEG is a relatively easy technique, with few complications, which is a good therapeutic option for the correction of chronic idiopathic gastric volvulus, especially in patients at high risk.

J. S. Baudet, J. R. Armengol-Miró, C. Medina, A. M. Accarino, J. Vilaseca, J.R. Malagelada

Dept. of Gastroenterology, Vall d'Hebron General Hospital, Barcelona, Spain

\section{References}

1. Gauderer MW, Ponsky JL, Izant RJ Jr. Gastrostomy without laparotomy: a percutaneous endoscopic technique. J Pediatr Surg 1980; 15: 872-5.

2. Ponsky JL, Gauderer MW. Percutaneous endoscopic gastrostomy: indications, limitations, techniques, and results. World J Surg 1989; 13: 165-70.

3. Moran BJ, Taylor MB, Johnson CD. Percutaneous endoscopic gastrostomy. Br J Surg 1990; 77: 858-62.

4. Eckhauser ML, Ferron JP. The use of dual percutaneous endoscopic gastrostomy (DPEG) in the management of chronic intermittent gastric volvulus. Gastrointest Endosc 1985; 31: $340-2$.

Corresponding Author

J. S. Baudet Arteaga

Dept. of Medicine, Division of Gastroenterology Complejo Hospitalario Ntra. Sra. de Candelaria

Carretera del Rosario s/n

$\mathrm{S} / \mathrm{C}$ de Tenerife 38010

Canary Islands

Spain

Fax: +34-3602337 